\title{
Parallelism of Words and their Socio-cultural Implications in Hamid Khan's Velvet of
}

\section{Loss}

\author{
* Abdul Karim Khan, Assistant Professor (Corresponding Author)
}

\begin{abstract}
This paper analyses the parallel words that occur in various poems of Hamid Khan in the collection, "Velvet of Loss". These words are: night, bird, dream, dawn, life, mist, dusk, and hope. The analysis of the words is based on foregrounding that is subcategorized as deviation and parallelism. Here, for the sake of brevity and restrictions of the space, only parallelism is taken into consideration and that too is delimited to the frequency of the above mentioned words in various poems of the entire collection, "Velvet of Loss". These words are tabulated with the page numbers of the book and frequency of repetition. Moreover, these words are also shown in the 3-D pi-chart so that their frequency could be highlighted in percentage as well. This is done in order to make it reader-friendly. In addition, the words are contextualized and taken into consideration with reference to the time frames of past, present and future. Lastly, the socio-cultural implications that are foregrounded are also mentioned. This article will lead other researchers to novel directions to probe into Pakistani poetry in English. This will add to their methods of objective analysis.
\end{abstract}

Keywords: Parallelism, Hamid Khan, socio-cultural connotations, Velvet of Loss

Introduction

Pakistani Literature in English has become a separate subject of interest for young scholars. This was made attractive by the epoch making venture of Tariq Rahman in the form of writing the A History of Pakistani Literature in English in 1990. It covers all the known literary works by the writers of Pakistani origin both inside and outside of Pakistan. It gives special attention to poetry, though it contains lists of dramas and novels as well. Moreover, it provides a guideline to young scholars for searching an area of exploration of their choice. Wilma Blue (first para) comments on Tariq Rehman's book, A History of Pakistani Literature in English that it is like an encyclopedia. One can learn a lot from it. In the same line of review, Mary Tobin (first para) states the Tariq Rehman's History gives you useful facts about the nature of Pakistani literature in English.

Omar Tarin, Ilyas Khan, and Majied (2015) trace Pakistani Literature in English to the 1920s. It was the time when the sense of nationalism was getting strong foothold. They discuss the notable writers of the sort, such as Chattopadhyay, M.A. Rashid, Raja Rao, Sarojini Naidu, and Mumtaz. Besides, there were a travelogue by Sake Deen Mahomet, and translations from Bengali into English of Rabindranath Tagore by himself. In this connection, Hamid Khan, too, needs proper attention, as he, like many other local writers, tries to attract our attention towards the problems of the modern man, especially those of Pakistanis.

Hamid Khan is a local poet writing in English. He did his PhD in English. Khan writes poetry in English centering both local and worldwide issues and human failings such as war, oppression, women rights, corruption, and hypocrisy, to mention a few. He does so through the tools of foregrounding, i.e. deviation and parallelism. His poetry is very terse and stenographic and, more often, grips the reader's attention through unusual usage of linguistic choices. Moreover, his poetry carries deviation on various levels, such as syntactic, semantic and graphological. As far as parallelism is concerned, he maintains it through phonemes as well as repetition of certain words that connote socio-cultural implications especially in the context of Pakistan and generally elsewhere in the world. It is needful to explore the hidden messages, in such type of poetry as Khan's, through the tools of foregrounding.

* Department of English \& Applied Linguistics, University of Science \& Technology, Bannu Email: akarim.khan@yahoo.com 


\section{Method}

Toolan (1990) states that stylistic analysis that it can be used even for the teaching of language and of literature. He further avers that it helps in exploring the diverse reading of similar texts and

"It can be used to assist in seeing features that might not otherwise have been noticed. It can shed light on the crafted texture of the literary text, as well as offering a productive form of assistance in completing interpretations, making them more complex and richer. Stylistics can thus be used both as a descriptive tool and as a catalyst for interpretation." (42)

In this connection, Fauconnier and Turner (2002) opine that despite the fact that both poetic and conventional languages integrate conceptually on the basis of certain principles, they are different at the same time. For instance, the divergence in the grammar of a poet is based on the poet's perception of the world around them.

Likewise, Leech (1969) states that without going back to linguistic notions and concepts much of the terms of literary criticism cannot possibly be explained such as metaphor and irony, etc. Stylistic analysis can be carried out through various levels, such as at the level of: graphology, phonology, morphology, and lexico-syntax. About lexico-syntax level of analysis Tallerman (1998) quoted in Imran Hussain \& Sana Mansoor (2017) states that "Lexico-Syntactic choices are obtained through devices such as piling of usual collocates, unusual collocates, archaic words, particular parts of speech, metaphor, simile, oxymoron etc" (P. 1) It depends upon the choice of the researcher whether they choose one, two or more levels to look through a piece of literature. In this connection, Leech and Short (1981) states that there are four ways to analyze texts: syntax, phonology, semantics and graphology. Alabi (2008) explains that graphological features include the foregrounded punctuation marks, italics, spacing, and size of print, etc.

Again, I. A. Richards (1929) points out four types of textual functions and meanings that are, sense, feelings, tone, and intention. In addition, Jacobson's (1961) six functions are more elaborate in this connection. They are: referential, emotive, conative, phatic, poetic, and meta-linguistic. Among them the poetic function stands out which according to Jacobson (1960: 358) "the poetic function projects the principle of equivalence from the axis of selection into the axis of combination'. On the other hand, Halliday's (1967) describes three major functions viz., "ideational, interpersonal and textual" (Leech \& Short, 1981, p. 30), though Fairclough (1995, p 4) explains that written texts are "multi semiotic" and exploit various forms of graphic designs apart from sound effects, diagrams and photographs.

In this paper, the poems are analyzed on the basis of foregrounding. The main tools of foregrounding are deviation and parallelism. This categorisation is mentioned by Martindale (2007), quoted in Lesley Moss (2014) which is also supported by Van Peer and Hakemulder (2006), and Shen (2007). After sifting Hamid Khan's poetic collection, Velvet of Loss, certain words struck the attention of the scholar as those words occur frequently at various places. This parallel occurrence of words project issues and problems related to the world around us. Their frequency is noted and they are compared as to which ones occur more frequently than the others. These words are also tabulated with the book page numbers and their frequency for ready reference. Their occurrence is also shown through 3-D pi-chart that shows percentage of the occurrence of the words. This method is delimited to parallelism of words only due to restrictions of the space.

\section{Analysis}

The frequency of words was noted in the whole of the collection, Velvet of Loss and then they were contextualized on the basis of the central ideas of the poems in which they occur. Their relevance to the socio-cultural issues were also taken into consideration with special reference to the three time frames - past, present and future. These words are: night, bird, dream, dawn, life, mist, dusk, and hope. Following is their detail.

\section{Night}

The word night is repeated eleven times in the collection, Velvet of Loss: new metaphor/In the night wind (p. 18); But the night/ still looms large (p. 20); waited/for the night to come (p. 22); in the cold/ of an unfriendly night (p. 26); night encroached upon/ a lonely star (p. 35); that this insatiable night/ is a curse (p. 37); a relaxed January Night.../ while the night/ is a curse (p. 41); the night/ kisses/ the light off (p. 43); the night deepens (p. 51); night/ has melted...sets to fight/ the evils/ of the night (p. 52); hours of the night.../ one night (p. 60) 
Eleven times repetition grips the reader's attention for curiosity. It is the night that creates darkness and dims the stars. The word, star is qualified by lonely thereby creating a transferred epithet that it is the poet that is lonely not the star. Thus, the night is a curse though it is awaited. If the lonely star is taken for the sun then the night ironically connotes the day. However, whether it is day or night, it represents human life as the repetition of it makes life of people.

When the word night is mentioned with reference to the present time (p. 18, 20, 26, 35, 37, 41 , and 43), it suggests hopelessness and a sense of tension, but when it is put in future time frame (p. $22 \& 60$ ), it suggests better life. It occurs in present time frame only once in the entire collection, Velvet of Loss where it is proceeded by the idea of hope. It also suggests nostalgia when the speaker says, the night deepens/and I think of you. (p. 51)

Thus, repetition of the word night represents human life and suggests hopelessness as there is no way out due to lack of light for guidance.

\section{Bird}

The bird occurs ten times in this collection: what is life?...of migratory birds(p. 16); crows in flocks (p. 17); sonorous song/ of a sky lark (p. 19); and birds/ are free to sing (p. 20); to catch the bird (p. 21); and the lonely bird(p. 22); the crows/ are not gullible (p. 25); cold iron/ clamped on a free bird (28); and a rooster/... a sparrow chirps (p. 30); birds in pairs (p. 32)

Taking the occurrence of the word bird as a whole, it comes with negative suggestion only thrice (p. 21, 22, \& 28), whereas it occurs seven times with positive suggestions (p. 16, 17, 19, 20, 25, $30, \& 32$ ). Moreover, the present tense is kept parallel for four times, then it is released through the inclusion of future time, and is kept parallel, again, twice, which, in turn, released, this time, through past tense followed by paralleled present tense. All the three time frames are put together for giving a sense of human life as a whole where little attention is focused on the future planning or no lesson is learnt from the past as is foregrounded through their one-time occurrence. The word "bird" is foregrounded through its repetition in the present context predominantly as happy-go-lucky one, though the surroundings put hurdles in its smooth way of life thereby suggesting the advocacy of women rights of freedom.

To put the bird in all the three time frames foregrounds the women condition in the context of Pakistan. On one side the skylark sings songs and on the other the lonely bird is imprisoned. The specification of the bird as skylark, sparrow, and crows foregrounds the idea that, in our part of the world, only those ladies enjoy their life who have earned a name or who are not dependent on their male counterparts. Similarly, the generalization of the bird in the collection, as bird foregrounds that generally women are not given importance in the patriarchic society as is ours in Pakistan.

\section{Dream}

It occurs seven times: Where dream should have been (p. 25); I keep on dreaming (p. 27); ... and hold on to my dream (p. 28); A wayward dream; (. . 30); the dream/... rewinds in remorse ( $p$. $31) ; . .$. with the beat of dream; a deodasi... capturing her dream (p. 36); and a lonely dream (p. 41)

The past time reference is altogether avoided with respect to the concept of dream which foregrounds that one should forget about the past and move forward, though the future time reference through the word dream suggests hopelessness (p. 25). It is put in contrast to the three-time reference to hope in the present time (p. 27, 28, \& 36), though it is made conditional with aimed motion, as when the movement is aimless, it reeks hopelessness (p. 31). The dream that unfolds the dual situation of hope and hopelessness across the present and future time frames foregrounds the inconsistency of mind of the modern man. It is also furthered through the body movements of deodasi. The materialization of the abstract idea of dream (capturing her dream) foregrounds the practical steps that are to be taken by the needy and destitute of the society for fulfilling their wishes in this world. In this regard, it is a criticism on the listlessness of man on one side, and aimless turmoil of them on the other.

\section{Dawn}

The word dawn occurs thrice in the collection: a wayward dawn (p. 27); the dawn will settle (p. 51); A new dawn is breaking (p. 52)

The repetition of dawn gives two positive clauses and one negative phrase. In the statement, $a$ new dawn is breaking there is hope; same idea is implied in the new dawn will settle, whereas the phrase a wayward dawn gives negative connotation if taken one of its lexical meanings i.e. unmanageable. The message of hope is put in future time whereas the message of hopelessness is put 
in the present tense which foregrounds that though, at present, the human condition is bad, yet every problem will be resolved in future and one must be hopeful about that. The same idea is strengthened through the use of present progressive aspect for the near future: A new dawn is breaking. (p. 52)

In addition, the word dawn is put only in the time frames of present and future, neglecting the past time frame altogether which foregrounds the idea that what is preceded by dawn is nothing but a dark night full of mystery and ambiguity. It also foregrounds the message that reckoning of the past should be avoided as it is of no use to harp on the same string, rather one should move forward for betterment.

5. Life

The word life is repeated thrice. Ours/ is a sad life (p. 26); of a loveless life (p. 42); for the love of life (p. 52)

About life the poet is disappointed as the repetition of the word life is qualified by the negative adjectives i.e. sad and loveless. Even the phrase for the love of life connotes despondence as it is for the love of life that the artist tries to fight the evils of the night (P. 52).

The future and past time references with respect to life are avoided which foregrounds the current human condition. Moreover, the thrice occurrence of life also foregrounds the three phases of human existence acceptable to most of the world religions - life before birth; life in this world; and life after death. In this regard, the present time reference shows life in this world. This gives the message that one should take into consideration the bad condition of life in this world as is foregrounded through the generalization of life that it is both loveless and sad.

6. Mist

It occurs twice: and the thickening mist (p. 29); The mist is thickening (p. 31)

The focus on the current bad condition of human life is stretched through the repetition of the word mist. This is foregrounded through its putting in the present time frame only - the past and future are avoided in this poetic collection. Moreover, no progress has been made so far in bringing about positive change in life in general, as is foregrounded through the twice occurrence of the same sentence but with altered word arrangement, i.e. and the thickening mist (p. 29); The mist is thickening (p. 31). This furthers the idea that the problems of life are increasing but there is lack of interest and laziness that do not let the problems to be solved. The thickening of the mist suggests severity of problems on one side and inactivity on human part on the other.

7. Dusk (p. 49).

This word also occurs twice: the evening/ melts in regrets. (p. 32); in the dusk he laid to rest

The concept of end of the day is shown twice through the words, evening and dusk. The past time reference is used for the dead body that represents the death toll during war as is contextualized in Africa, whereas the present time reference is used in the personification of evening that melts in regrets. This foregrounds that life on earth has become so miserable that death sounds good instead to the departed soul, which is implied in the noun, rest, though for the successors the condition is unbearable, which is implied in regrets. The avoidance of future time reference foregrounds that the war-torn belts of the world have no future at all, or if there is any future, in the real sense of the word, then it would be bleak and black as night. The concept of war is discussed, here, with reference to the poems in which the words evening, and dusk occur, i.e. By the Nile and Africa - II.

8. Hope

It also occurs thrice in the collection: and so she left/...hoping to find/ another house (p. 34); There is hope./Still there is hope (p. 54)

First, it occurs in the poem The Sin where a poor lady is hopeful for finding some job to support her family with, and, secondly, it occurs in the poem, Bosnia-II. The time frames are present and past apparently leaving the future, though it is implied in the very word, hope. In a war stricken area, such as, Bosnia, one can only hope for a better human condition, as hope is the only and last shelter of the desperate and destitute. Moreover, the repetition of the noun, hope in consecutive lines in the poem, Bosnia - II, stresses the need of hope, which further foregrounds that whosoever visits these miserable people, they do nothing for them practically, hence they are thrown to the lap of hope only. Similarly, the present condition of the widowed women is highlighted through their search for a living, keeping in touch with hope for the satisfaction of their derelict heart. 
The above mentioned detail of the repetition of words is shown through the table below for a compact glimpse of them:

\section{Table of the Repeated Words}

\begin{tabular}{clll}
\hline No & Word & Number of Repetition & Book Page no \\
\hline 1 & Night & Eleven times & $18,20,22,26,35,37,41,43,51,52,61$ \\
2 & Bird & Ten times & $16,17,19,20,21,22,25,28,30,32$ \\
3 & Dream & Seven times & $25,27,28,30,31,36,41$ \\
4 & Dawn & Thrice & $27,51,52$ \\
5 & Life & Thrice & $26,42,52$ \\
6 & Mist & Twice & 29,31 \\
7 & Dusk & Twice & 32,49 \\
8 & Hope & Thrice & 34,54 \\
\hline
\end{tabular}

The repetition of the words is shown through 3-D Pi-Chart also in order to have an overall idea of the occurrence of the words in respect of percentage.

\section{Pi-Chart for the Repeated Words}

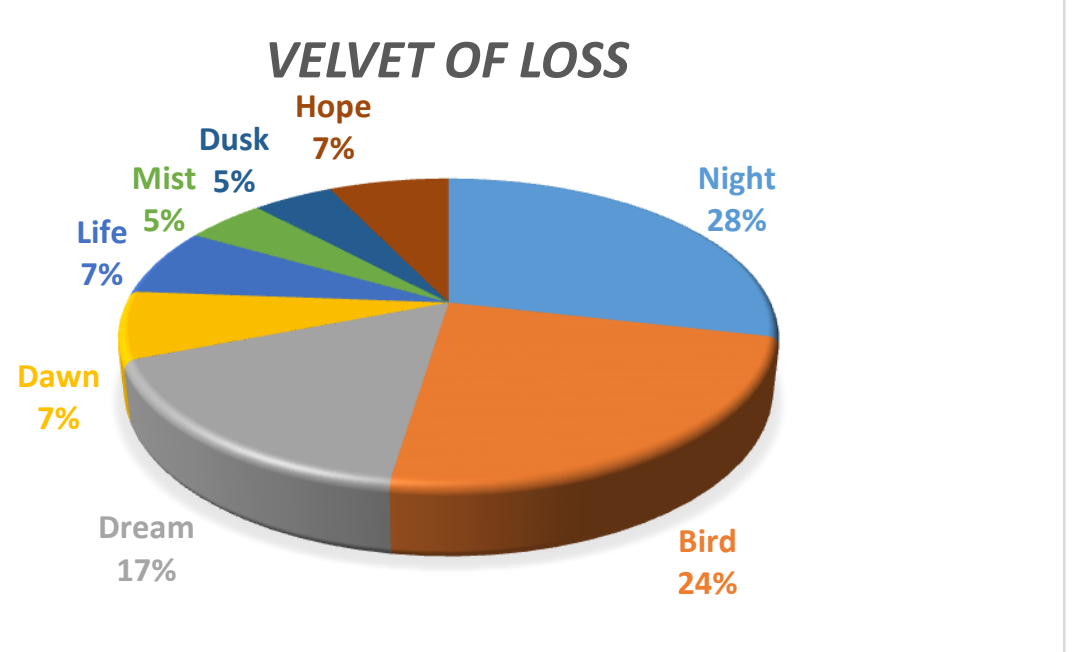

By putting the repeated words, in respect of their occurrence of times, in the 3D Pi-Chart, it shows that night occupies the highest place in the overall thematic inferences in Khan's poetry. It foregrounds the overwhelming terror, obscurity, confusion, dilemma, uncertainty, and nightmares of modern man chiefly in the context of Pakistan envisioned by Khan. Next is the occurrence of the word, bird, gives us the clue that it is the bird that mostly lives in the dark. If we take the bird ${ }^{1}$ for women then it gets clear that they are put behind the walls for household chores in the poet's part of the world. They are devoid of the basic facilities of life and even basic rights are denied to them. The detail, in this regard is given under the theme of Women oppression in the same chapter. Among night, bird, and dream, the word dream stands third in respect of repetition; but it shows closeness, in comparison to other words. In this regard, it is appropriate to connect them for meaningful interpretation. The bird is dreaming during the night. Keeping in view the context in which the words occur, it is suggested that the dream is not a pleasant one - It is nightmarish. But at the same time, taking the denotative meaning of the dream, it can both be good or bad. On one side it is nightmarish in the sense that the women are put to drudgery only at home, and on the other hand, it is a dream of hope for the better, which can be taken for the unconscious desire of the women in bondage, so to speak.

More interestingly, the words dawn, life, and hope occur in the same ratio of percentage shown in the 3-D Pie Chart. They are connected for their closeness and relatedness. Man begins a new life at dawn while getting up from short span of death (sleep) and binds themselves with the rope of hope. Every new day gives humans a sense of relief and eagerness to do something. But, in comparison to the dismal situation connoted through the other words in the chart, the element of hope

\footnotetext{
${ }^{1}$ The word bird is normally used as a metaphor for beloved, girl or generally for women in the vernacular literature of the province, Khyber Pakhtunkhwa which is the ancestral area of the poet. More often the word occurs in various hyponymic forms in Pashto literature, such as bulbula (bulbul), kontaraor kamtara (pigeon), or zanrha (crane), etc, to name a few.
} 
is wavering to a negligible degree. This gives us the overall effect of sadness on human personality. The cup for most of the people in today's scenario is often half-empty. In this regard, it is criticism on the current demoralized and despondent condition of the people around us, hence the poet indirectly desires that his coreligionists and brethren had come out of sluggishness and cynicism and start with new zeal and enthusiasm to uplift the society. It is high time for the youth of the society to muster up courage and rebuild what has been demolished.

Going back to the chart again, it becomes clear that hope for the better gains more repetition than the mist and dusk, which again suggest that apparently during misty and prevalent darkish day nothing can be gained of importance, but to compare the number of occurrence of the mentioned words, the overall foregrounded notion is that nothing is dark or unachievable, rather it is enthused in human mind; it is there in man's psyche when they get disappointed or when they are sad. Thus, Khan wants to encourage his people not to be afraid of failure or mishaps, rather one should be hopeful and courageous enough to alter for good what seems bad for them.

\section{Conclusion and Discussion}

The parallel occurrence of words connotes various themes with respect to time frame. It is the night that brings darkness and dims the star. The star is qualified by lonely thereby giving a transferred epithet that the star cannot be lonely rather the poet is. If the lonely star is taken for the sun then the night is ironically used for the day. Anyhow, whether it is day or night, it can be taken as human life as a whole because the repetition of it makes life of people.

The word night suggests hopelessness and a sense of tension, but when it is put in future time frame, it gives the message of better life. It also gives the idea of hope.

The word, bird, excels in positive suggestion as it comes with negative suggestion only thrice. Moreover, all the three time frames are put together for giving a sense of human life as a whole where little attention is given to the future planning or no lesson is learnt from the past. The word, bird, suggests that the surroundings put hurdles in the bird's (woman's) smooth way of life thereby suggesting the advocacy of women rights of freedom. Similarly, the generalization of the bird in the collection, as bird foregrounds that generally women are not given importance in the patriarchic society as is ours in Pakistan.

The word, dream, foregrounds that bygones are bygones and that one should move forward, though at the same time it suggests hopelessness. The dream also foregrounds the inconsistency of mind of the modern man. Moreover, the materialization of the abstract idea of dream foregrounds the practical steps that are to be taken by the people to reform their society.

The repetition of dawn gives the message of hope as well as hopelessness which projects the idea, at present, the human condition is bad, yet every problem will be resolved in future hopefully. In addition, the word dawn foregrounds the idea that what is preceded by dawn is nothing but a dark night full of mystery and ambiguity. It also projects the message that reckoning of the past should be avoided as it is of no use, rather one should move forward for betterment.

About life the poet is disappointed. Moreover, the thrice occurrence of life also foregrounds life before birth; life in this world; and life after death. This gives the idea that one should take into consideration the bad condition of life in this world. The focus on the current bad condition of human life is stretched through the repetition of the word mist. Moreover, no progress has been made so far in bringing about positive change in life in general. This shows that the problems of life are increasing but there is lack of interest and laziness that do not let the problems to be solved.

The concept of end of the day is shown twice through the words, evening and dusk. They foreground that life on earth has become so miserable that death sounds good instead to the departed soul. The avoidance of future time reference foregrounds that the war-torn belts of the world have no future at all, or if there is any future, in the real sense of the word, then it would be bleak and black as night.

Hope occurs in the poems The Sin and Bosnia - II. In a war stricken area, such as, Bosnia, one can only hope for a better human condition, as hope is the only and last shelter of the desperate and destitute. The word, hope, also projects the idea that whosoever visits these miserable people, they do nothing for the bereaved practically. It is high time for the youth of the society not to lose nerve and rebuild what has been destroyed. Thus, Khan wants to encourage his people not to be afraid of failure or mishaps, rather one should be hopeful and courageous enough to reform their society. 
Khan has tried to, in his own peculiar style, to aware the reader to the issues surrounding them. Once awareness and consciousness are attained then it becomes easier for humans to reform themselves and their society. His repetition of the thematic words attracts the attention of the readers thereby compelling them to ponder and go deep into the matter.

\section{References}

Alabi, T. A. (2008). "Phonolexical foregrounding in Oduduwa and Sango as Samples of Traditional Religious Drama in Nigeria". In Atoye, R. O. (Ed.). Papers in English and Linguistics. Vol. 9.

Blue, W. (n.d) Review of Tariq Rehman'sPakistani Literature in English. https://alaphomez.firebase app.com Retrieved 05 March, 2018.

Fairclough, N. (1995). Critical discourse analysis. Harlow: Longman.

Fauconnier, G. and Turner, M. (2002) The Way We Think: Conceptual Blending andthe Mind's Hidden Complexities New York: Basic Books.

Halliday, M. A. K. (1973). Explorations in the Functions of Language London: Edward Arnold.

Hosain, S. (1965). First Voices. Six Poets from Pakistan: Ahmed Ali, ZulficarGhose, ShahidHosain, RiazQadir, TaufiqRafat, ShahidSuhrawardy.https://books.google.com.pk. Retrieved 11 Jan, 2017.

Jakobson, R. (1966). "Grammatical parallelism and its Russian facet". Language 42 (2): 399429.http://www.jstor.org/stable/411699.

Khan, H. (2002). Velvet of Loss. Dr Abdul Malik Book Foundation, Malakand Agency. Atifaq Press Peshawar.

Leech, G. N. (1969). A Linguistic Guide to English Poetry. Harlow: Longman.

Leech, G. and Short, M. (1981). Style in Fiction Harlow: Longman.

Moss. L. (2014). Corpus Stylistics and Henry James's Syntax. http://discovery.ucl.ac.uk/ 1461029/1/Lesley_Moss_thesis\%5B1\%5D.pdf Retrieved 15 March, 2016.

Rahman, T. (1991) A History of Pakistani Literature in English.Lahore: Vanguard. (Republished 2005)

Richards, I. A. (1926). Practical Criticism. 2nd edition. London: Routledge \& Kegan Paul.

Shen, Y. (2007). Language and Literature: Foregrounding in Poetic Discourse. URL:http://lal. sagepub.com

Tarin, O. et al (2015) Pakistani English Literature - A Introduction, 1947 to the Present Posted by Prachaya.http://www.prachyareview.com/pakistani-english-literature-a-brief-introduction1947-to-the-present-by-omer-tarin-ilyas-khan-and-k-majied/ Retrieved 5 January, 2018.

Tobin, M. (n.d) Review of Tariq Rehman'sPakistani Literature in English. https://alaphomez.firebase app.com Retrieved 05 March, 2018.

Toolan, M. (1990) The Stylistics of Fiction: A Literary-linguistic Approach London:Routledge.

van Peer, W. \&Hakemulder, F. (2006) Foregrounding. https://www.researchgate.net/publication/ 46690484_Foregrounding. Retrieved 13 March, 2017 